\section{Cellular Uptake but Low Permeation of Human Calcitonin-Derived Cell Penetrating Peptides and Tat(47-57) Through Well-Differentiated Epithelial Models}

\author{
Rachel Tréhin, ${ }^{1}$ Ulrike Krauss, ${ }^{2}$ Annette G. \\ Beck-Sickinger, ${ }^{2}$ Hans P. Merkle, ${ }^{1}$ and Hanne M. \\ Nielsen ${ }^{1,3,4}$
}

\section{Received December 19, 2003; accepted March 8, 2004}

\begin{abstract}
Purpose. To investigate whether cell penetrating peptides (CPP) derived from human calcitonin (hCT) possess, in addition to cellular uptake, the capacity to deliver their cargo through epithelial barriers. Methods. Cellular uptake of hCT(9-32) and permeation of six hCTderived peptides, namely, hCT(9-32), hCT(12-32), hCT(15-32), $\mathrm{hCT}(18-32), \mathrm{hCT}(21-32)$, and a random sequence of hCT(9-32) were evaluated in fully organized confluent Madin-Darby canine kidney (MDCK), Calu-3, and TR146 cell culture models. For comparison, Tat(47-57) and penetratin(43-58) were investigated. The peptides were $\mathrm{N}$-terminally labeled with carboxyfluorescein $(\mathrm{CF})$. Uptake in the well-differentiated epithelial models was observed by confocal laser scanning microscopy (CLSM), whereas permeation through the models was analyzed by reversed-phase (RP)-HPLC.

Results. In MDCK epithelium hCT(9-32), Tat(47-57) and penetratin(43-58) demonstrated punctuated cytoplasmic distribution. In Calu-3, Tat(47-57) and penetratin(43-58) were simultaneously localized in a punctuated cytoplasmic and paracellular distribution, whereas hCT(9-32) showed strict paracellular distribution. By contrast, in TR146 cells, Tat(47-57) was located strictly paracellularily, whereas penetratin(43-58) showed a punctuated cytoplasmic pattern and hCT(9-32) both. The transepithelial permeability of all tested peptides and their cargo was lower than that of paracellular markers. Conclusions. The CPP uptake pattern depends on both the type of peptide and the cell culture model. In general, the investigated CPP have no apparent potential for systemic drug delivery across epithelia. Nevertheless, distinct patterns of cellular distribution may offer a potential for localized epithelial delivery.
\end{abstract}

KEY WORDS: cell penetrating peptides; cellular translocation; epithelial permeability; epithelial metabolism; human calcitonin.

\section{INTRODUCTION}

Because of the restricted cellular access and permeability of many polypeptide and nucleic acid therapeutics, interest in cellular drug delivery systems has been intense. A common difficulty for more widespread use of these biomacromolecules is their low resistance to extracellular cleavage at the

\footnotetext{
$\overline{{ }^{1} \text { Department of Chemistry and Applied BioSciences, Swiss Federal }}$ Institute of Technology Zurich (ETH Zürich), 8057 Zurich, Switzerland.

${ }^{2}$ Institute of Biochemistry, University of Leipzig, 04103 Leipzig, Germany.

${ }^{3}$ Department of Pharmaceutics, The Danish University of Pharmaceutical Sciences, 2100 Copenhagen, Denmark.

${ }^{4}$ To whom correspondence should be addressed. (e-mail: hmn@ dfuni.dk)
}

site of administration and their low penetration and permeation rates in epithelial and endothelial barriers. In order to overcome these limitations, cell penetrating peptides (CPPs) may offer unprecedented advantages for intracellular delivery. In vivo studies in mice with Tat(47-57) actually showed that this polycationic CPP derived from the human immunodeficiency virus Tat protein triggered great expectation as it appeared to help a marker protein pass several biological barriers, even the blood brain barrier, after i.p. injection, and distribute into virtually every organ (1). Most CPPs are derived from naturally occurring protein sequences, which possess the remarkable ability to cross the plasma membrane and even reach the nuclear regions of cells. CPPs have been described in literature as having the ability to enter a large number of different cell types (2-8) and facilitate the cellular translocation of various macromolecular cargos such as proteins (9), DNA oligomers (10), and peptide-nucleic acids (PNA) $(11,12)$, or particulates like liposomes (13) and magnetic nanoparticles (14). In a previous study, we demonstrated that truncated sequences of the human calcitonin (hCT) such as hCT(9-32), hCT(12-32), hCT(15-32), and hCT(18-32), as well as Tat(47-57) and penetratin(43-58), were internalized in Madin-Darby canine kidney (MDCK) cell monolayers (15). Additionally, $\mathrm{hCT}(9-32)$ was shown to translocate through the plasma membrane of excised bovine nasal mucosa $(16,17)$ and to act as a transfer vehicle for green fluorescent protein (GFP) in this tissue model (18). Tat peptides and penetratin were demonstrated to permeate the plasma membrane of various cell lines (2-5).

Nevertheless, most in vitro studies have been performed in proliferating cell cultures, only few in fully organized absorption barrier models, such as the MDCK epithelial cell culture model $(15,19,20)$ and the Caco-2 epithelial model $(19,21)$, and none in endothelial models. We believe, however, that only fully organized confluent cell barriers represent relevant in vitro models to study the benefits of CPP in improving the bioavailability of biomacromolecular therapeutics. The cell culture models MDCK, Calu-3, and TR146 represent three distinct types of epithelia featuring specialized properties in terms of cell-to-cell junctions, cell morphology and function as physiologic absorption barrier. MDCK cells represent a distal renal epithelial cell line forming a continuous sheet of identically oriented asymmetrical cells joined by tight junctions. This cell line was chosen as a general model for columnar-type absorptive epithelia with tight junctions. When subcultured on proper support, reconstructed cell layers possess transport and permeability qualities similar to that of absorptive epithelia in vivo (22). Systemic drug delivery through airway or buccal epithelium is an attractive concept, which might be improved using CPP. Calu-3 represents a human bronchial submucosal adenocarcinoma cell line that forms tight, polarized, and well differentiated monolayers with apical microvilli and tight-junctional complexes (23). In contrast to MDCK, Calu-3 generates extracellular mucus. Calu-3 monolayers have been described as a potentially useful model when assessing drug permeability in airway epithelia $(24,25)$. Finally, the TR146 cell line originates from a neck node metastasis of a human buccal carcinoma (26). When subcultured on filters, TR146 cells express ultrastructural characteristics similar to normal human buccal epithelium (no tight junctions) and represents an in vitro model of the human 
buccal epithelium (27) or, in more general terms, for other stratified squamous epithelia, for example, the rectal or the vaginal mucosa. It has been successfully used for buccal permeability studies $(27,28)$.

The purpose of the current study was to initially compare the cellular uptake of N-terminally carboxyfluorescein (CF)labeled hCT(9-32), Tat(47-57), and penetratin(43-58) in the three epithelial models. In a second step, we evaluated whether these peptides-once internalized-would be able to permeate through confluent MDCK, Calu-3, and TR146 epithelial-type cell layers, which are all representing established in vitro models for systemic drug delivery.

\section{MATERIALS AND METHODS}

\section{Materials}

MDCK cells (low resistance, type II) were a gift from the Biopharmacy group of ETH Zurich (Zurich, Switzerland). Calu-3 cells were purchased from American Type Culture Collection ATCC (Rockville, MD, USA), and TR146 cells from Imperial Cancer Research Technology (London, UK). Cell culture media, L-glutamine, trypsin-EDTA, penicillin, streptomycin, and Hanks' Balanced Salt Solution (HBSS) were from Life Technologies (Basel, Switzerland). Fetal calf serum (FCS) for the MDCK cells was obtained from Winiger AG (Wohlen, Switzerland) and for the TR146 cells from PAA laboratories (Linz, Austria). For the Calu-3 cells, FetalClone III serum was from HyClone (Logan, UT, USA). Vitrogen collagen was from Nutacon (Leimuiden, Belgium). Cell culture inserts (polyethylene terephthalate, $0.4-\mu \mathrm{m}$ pore size, $1.6 \times 10^{6}$ pores $/ \mathrm{cm}^{2}, 0.9$ and $4.2 \mathrm{~cm}^{2}$ growth area) and companion plates were purchased from Falcon (Becton Dickinson Labware, Franklin Lakes, NJ, USA). Glass chamber slides were obtained from Nunc (Wiesbaden, Germany), and 96well plates from TPP (Trasadingen, Switzerland).

Hoechst 33342 was purchased from Molecular Probes (Leiden, Netherlands) and the MTS/PMS cytotoxicity assay from Promega (Madison, WI, USA). 5-carboxyfluorescein and 5(6)-carboxyfluorescein (CF) was from Fluka (Buchs, Switzerland), $\left[{ }^{3} \mathrm{H}\right]-$ mannitol $(19.7 \mathrm{Ci} / \mathrm{mmol}),\left[{ }^{3} \mathrm{H}\right]-$ polyethyleneglycol-900 (PEG900, $2.02 \mathrm{mCi} / \mathrm{g}$ ), and $\left[{ }^{3} \mathrm{H}\right]-$ polyethyleneglycol-4000 (PEG4000, $1.5 \mathrm{mCi} / \mathrm{g}$ ) from $\mathrm{NEN}$ Life Science Products, Inc. (Boston, MA, USA). All other chemicals were from Sigma (St. Louis, MO, USA).

\section{Methods}

\section{Synthesis of Peptides, CF-Labeling, and Identification}

Linear hCT fragments used for the uptake study were synthesized according to Rist et al. (29) by automated multiple solid-phase peptide synthesis using a robot system (Syro, MultiSynTech, Bochum, Germany), CF-labeled and identified as described previously (15). For the permeability study, hCT fragments with a purity of $>95 \%$ were labeled with the 5-carboxyfluorescein isomer; and the peptides were purchased from NMI (Reutlingen, Germany). Synthesis and identification of CF-labeled Tat(47-57) and penetratin(43-58) were performed by the group of Professor B. Gutte (Institute of Biochemistry, University of Zurich), and carried out as described previously (15). All synthesized peptide sequences are compiled in Table I.

\section{Cell Culture}

Cells were cultured under standard conditions at $37^{\circ} \mathrm{C}$ in a $5 \% \mathrm{CO}_{2}$ humidified atmosphere. For all three cultures the medium was supplemented with $10 \%$ (v/v) FCS and $1 \%$ penicillin/streptomycin. MDCK was cultured in minimum essential medium with Earl's salts (MEM) (30) and Calu-3 and TR146 in DMEM. For permeability studies, cells were cultured on inserts with a constant density of $2 \times 10^{4}$ cells $/ \mathrm{cm}^{2}$ for MDCK (on $4.2-\mathrm{cm}^{2}$ insert), $10^{5}$ cells $/ \mathrm{cm}^{2}$ for Calu-3 (on 0.9$\mathrm{cm}^{2}$ insert) and $24 \times 10^{3}$ cells $/ \mathrm{cm}^{2}$ for TR146 (on $0.9-\mathrm{cm}^{2}$ insert). For Calu-3, the filters were initially coated with collagen $(30 \mu \mathrm{g} / \mathrm{ml})$. The MDCK and TR146 cell cultures were cultured submerged. Post seeding onto the filter, the Calu-3 cells attached to the filter overnight and the medium was then removed from the apical compartment to allow the cells to form a monolayer at an air-liquid interface. Apart from the absence of liquid in the apical chamber, the Calu-3 cells were cultured as the TR146 cells $(27,31)$. MDCK monolayers (passage 227-235) were used after 10 days in culture, Calu-3 monolayers (passage 36-41) after 17 to 19 days, and TR146 multilayers (passage 11-15) after 28 to 30 days. Uptake studies were performed on glass chamber slides and cytotoxicity assays (MTS/PMS assay) in 96-well plates. For these studies, the cell seeding densities as well as the culturing time were identical to those used in the permeability study.

\section{Uptake Study}

Studies in living Calu-3 monolayers and TR146 multilayers were carried out at $37^{\circ} \mathrm{C}$ with horizontal mechanical shaking $(150 \mathrm{rpm})$. Cells were grown on glass chamber slides and equilibrated with HBSS for $30 \mathrm{~min}$ prior to the uptake studies. The buffer was then discarded and the cells further incubated in HBSS containing the appropriate concentration of CFlabeled peptides or unconjugated CF for $90 \mathrm{~min}$. The concentration of hCT(9-32), Tat(47-57), and penetratin(43-58) was $40 \mu \mathrm{M}, 10 \mu \mathrm{M}$, and $10 \mu \mathrm{M}$, respectively. Simultaneously, nuclei were stained with $1 \mu \mathrm{g} / \mathrm{ml}$ Hoechst 33342. Subsequently, cells were rinsed three times with HBSS and analyzed by confocal laser scanning microscopy (CLSM; Zeiss 410 inverted microscope, Zurich, Switzerland). Two-dimensional multichannel image processing was performed using the IMARIS software (Bitplane AG, Switzerland). MDCK cells were fixed before analysis (15); Calu-3 and TR146 cells were non-fixed.

\section{Permeability Study}

Prior to permeability measurements, following standard protocols, confluent MDCK cells were equilibrated for 30 min at $37^{\circ} \mathrm{C}$, Calu-3 and TR146 cells for $15 \mathrm{~min}$ at room temperature in HBSS ( $\mathrm{pH} 7.4$ ), and the transepithelial electrical resistance (TEER) was measured using a Millicell-ERS system (Millipore, Bedford, MA, USA). Permeability of the CF-labeled peptides, their CF-labeled metabolites, or radioactive labeled markers across epithelia was assessed in three different passages of cells in $\mathrm{HBSS}$ at $37^{\circ} \mathrm{C}$ using a plate shaker for agitation $(150 \mathrm{rpm})$ to ensure mixing and in order to minimize the aqueous boundary layer. Briefly, $0.8 \mathrm{ml}$ 
Table I. Amino Acid Sequences of hCT-Derived Peptides, Tat(47-57), and Penetratin (43-58) and Molecular Weight (MW) of All Compounds Used in the Current Study

\begin{tabular}{|c|c|c|c|c|c|c|c|c|c|c|c|c|c|c|c|c|c|c|c|c|c|c|c|c|c|}
\hline Compound & & & & & & & & & & & & equ & ence & & & & & & & & & & & & $\mathrm{MW} \dagger(\mathrm{Da})$ \\
\hline & $9 \ddagger$ & & & 12 & & & 15 & & & 18 & & & 21 & & & 24 & & & 27 & & & & 31 & & \\
\hline hCT(9-32) & $\mathrm{L}$ & $\mathrm{G}$ & $\mathrm{T}$ & $\mathrm{Y}$ & $\mathrm{T}$ & Q & $\mathrm{D}$ & $\mathrm{F}$ & $\mathrm{N}$ & $\mathrm{K}$ & $\mathrm{F}$ & $\mathrm{H}$ & $\mathrm{T}$ & $\mathrm{F}$ & $\mathrm{P}$ & $\mathrm{Q}$ & $\mathrm{T}$ & A & I & $\mathrm{G}$ & $\mathrm{V}$ & G & A & $\mathrm{P}$ & 2968.8 \\
\hline hCT(12-32) & & & & $\mathrm{Y}$ & $\mathrm{T}$ & Q & $\mathrm{D}$ & $\mathrm{F}$ & $\mathrm{N}$ & $\mathrm{K}$ & $\mathrm{f}$ & $\mathrm{H}$ & $\mathrm{T}$ & $\mathrm{F}$ & $\mathrm{P}$ & $\mathrm{Q}$ & $\mathrm{T}$ & A & I & $\mathrm{G}$ & $\mathrm{V}$ & G & A & $\mathrm{P}$ & 2697.5 \\
\hline hCT(15-32) & & & & & & & $\mathrm{D}$ & $\mathrm{F}$ & $\mathrm{N}$ & $\mathrm{K}$ & $\mathrm{F}$ & $\mathrm{H}$ & $\mathrm{T}$ & $\mathrm{F}$ & $\mathrm{P}$ & $\mathrm{Q}$ & $\mathrm{T}$ & A & I & G & V & G & A & $\mathrm{P}$ & 2305.1 \\
\hline hCT(18-32) & & & & & & & & & & $\mathrm{K}$ & $\mathrm{F}$ & $\mathrm{H}$ & $\mathrm{T}$ & $\mathrm{F}$ & $\mathrm{P}$ & Q & $\mathrm{T}$ & A & I & $\mathrm{G}$ & V & G & A & $\mathrm{P}$ & 1928.7 \\
\hline hCT(21-32) & & & & & & & & & & & & & $\mathrm{T}$ & $\mathrm{F}$ & $\mathrm{P}$ & $\mathrm{Q}$ & $\mathrm{T}$ & A & I & $\mathrm{G}$ & $\mathrm{V}$ & G & A & $\mathrm{P}$ & 1516.2 \\
\hline $\begin{array}{l}\mathrm{hCT}(9-32) \text { Derived } \\
\text { random sequence }\end{array}$ & $\mathrm{F}$ & $\mathrm{L}$ & $\mathrm{T}$ & A & G & Q & $\mathrm{N}$ & $\mathrm{T}$ & I & Q & $\mathrm{T}$ & $\mathrm{P}$ & $\mathrm{V}$ & $\mathrm{K}$ & $\mathrm{T}$ & G & $\mathrm{G}$ & $\mathrm{H}$ & $\mathrm{F}$ & $\mathrm{P}$ & $\mathrm{F}$ & A & $\mathrm{D}$ & $\mathrm{Y}$ & 2968.8 \\
\hline TAT(47-57) & $\mathrm{G}$ & $\mathrm{Y}$ & $\mathrm{G}$ & $\mathrm{R}$ & K & $\mathrm{K}$ & $\mathrm{R}$ & $\mathrm{R}$ & Q & $\mathrm{R}$ & $\mathrm{R}$ & $\mathrm{R}$ & $\mathrm{G}$ & & & & & & & & & & & & 2031.9 \\
\hline Penetratin (43-58) & $\mathrm{R}$ & $\mathrm{Q}$ & I & $\mathrm{K}$ & I & $\mathrm{W}$ & $\mathrm{F}$ & Q & $\mathrm{N}$ & $\mathrm{R}$ & $\mathrm{R}$ & M & $\mathrm{K}$ & $\mathrm{W}$ & $\mathrm{K}$ & $\mathrm{K}$ & & & & & & & & & 2604.7 \\
\hline $\begin{array}{l}\text { Mannitol } \\
\text { PEG900 } \\
\text { PEG4000 }\end{array}$ & & & & & & & & & & & & & & & & & & & & & & & & & $\begin{array}{r}182 \\
\sim 900 \\
\sim 4000\end{array}$ \\
\hline
\end{tabular}

All peptides are N-terminally ligated with 5(6)-carboxyfluorescein.

* hCT-derived peptides and penetratin(43-57) are C-terminally amidated. Tat(47-57) carries a glycine at both terminals.

$\dagger$ The MW of the peptides include the N-terminal 5(6)-carboxyfluorescein.

$\ddagger$ Numbering of hCT-derived peptides with respect to native human calcitonin.

(MDCK) or $0.5 \mathrm{ml}$ (Calu-3, TR146) of peptide solution was added to the apical side and $3 \mathrm{ml}$ (MDCK) or $1.8 \mathrm{ml}$ (Calu-3, TR146) of HBSS to the basal side. At selected time points, for a period of $6 \mathrm{~h}, 200 \mu \mathrm{l}$ samples were withdrawn, added to 10 $\mu \mathrm{l}$ of $3.7 \mathrm{M}$ acetic acid, and immediately replaced with $200 \mu \mathrm{l}$ HBSS. The peptide concentrations were $40 \mu \mathrm{M}$ for $\mathrm{CF}$ labeled hCT(9-32), hCT(12-32), hCT(15-32), hCT(18-32), and hCT(21-32) and $10 \mu \mathrm{M}$ for Tat(47-57). CF and the CF-labeled random sequence of $\mathrm{hCT}(9-32)$ at a concentration of $40 \mu \mathrm{M}$ were used as controls. The random sequence corresponds to a peptide containing the 24 amino acids of hCT(9-32) in a random position. The permeability of $\left[{ }^{3} \mathrm{H}\right]-$ mannitol $(4 \mu \mathrm{Ci} /$ $\mathrm{ml}),\left[{ }^{3} \mathrm{H}\right]$-PEG900 $(0.5 \mu \mathrm{Ci} / \mathrm{ml})$ and $\left[{ }^{3} \mathrm{H}\right]$-PEG4000 $(1 \mu \mathrm{Ci} / \mathrm{ml})$ was studied under the same experimental conditions. These markers were used as standards to validate the cellular integrity of the epithelial cell layer(s) and to monitor passive paracellular transport. Radiotracer samples were mixed with 2.0 $\mathrm{ml}$ scintillation cocktail (Ultima Gold, Perkin Elmer Life Sciences, Beltsville, MD, USA) and measured by liquid scintigraphy (Beckman Counter LS6500, Fullerton, CA, USA). In order to evaluate the free diffusion of the compounds through the cell culture inserts, control experiments (with $\left[{ }^{3} \mathrm{H}\right]-$ mannitol, $\left[{ }^{3} \mathrm{H}\right]-\mathrm{PEG} 900,\left[{ }^{3} \mathrm{H}\right]-\mathrm{PEG} 4000, \mathrm{hCT}(9-32)$, Tat(47-57) and penetratin(43-58)) were performed using inserts and collagen-coated inserts without cells.

\section{Preliminary Metabolism Study}

MDCK and Calu-3 cells cultured as for the permeability studies were incubated with $40 \mu \mathrm{M}$ CF-labeled hCT(9-32) at $37^{\circ} \mathrm{C}$ and shaking $(150 \mathrm{rpm})$ in the reflection kinetics mode (32). Briefly, the basal side was blocked with a polystyrene well plate as an impermeable barrier. Under such conditions no permeation through the epithelial models occurs, and metabolites accumulate in the apical compartment. At times $\mathrm{t}=$ 0 (MDCK, Calu-3), $60 \mathrm{~min}$ (MDCK, Calu-3) and $6 \mathrm{~h}$ (MDCK), 50- $\mu$ l samples were removed, added to $5 \mu$ of 3.7 $M$ acetic acid and analyzed by reversed phase (RP)-HPLC. For improved sensitivity, fluorescence detection was applied, i.e., only intact peptide and metabolites carrying the $\mathrm{N}$ terminal fluorophore were detected. In order to check whether the emitted fluorescence intensity of the CF was dependent on the length of the peptide residue, that is, the extent of metabolism, a second study with Calu-3 was carried out in parallel $(n=3)$. Samples of $150 \mu l$ were withdrawn at 0,20 , 40 , and $60 \mathrm{~min}$, and the intensity of fluorescence was measured by fluorescence spectrophotometry $\left(\lambda_{\mathrm{ex}} 492 \mathrm{~nm}, \lambda_{\mathrm{em}}\right.$ $517 \mathrm{~nm}$ ) (Varian CARY Eclipse, Zug, Switzerland).

\section{Cytotoxicity (MTS/PMS) Study}

Cells cultured in 96-well plates were incubated for 1, 2, 4, and $24 \mathrm{~h}$ with various concentrations of CF-labeled peptides ranging from $40 \mu \mathrm{M}$ to $100 \mu \mathrm{M}$ for hCT-derived peptides and from $10 \mu \mathrm{M}$ to $1000 \mu \mathrm{M}$ for Tat(47-57) and penetratin(43-58) $(\mathrm{n}=4)$. Concentrations higher than $100 \mu \mathrm{m}$ of the hCTderived peptides were not tested as the peptides had the tendency to aggregate at higher concentrations. As a control, $\mathrm{CF}$ $(1 \mathrm{mM})$ was incubated with the cells $(1,2,4$, and $24 \mathrm{~h} ; \mathrm{n}=4)$. MDCK cell monolayers were incubated with hCT(9-32), hCT(18-32), Tat(47-57), and penetratin(43-58). Calu-3 and TR146 cell layers were incubated with hCT(9-32), hCT(1232), Tat(47-57), and penetratin(43-58). At the end of the incubation time, the peptide solutions were discarded and replaced by the MTS/PMS solution. Briefly, $100 \mu$ l of PMS (0.92 $\mathrm{mg} / \mathrm{ml})$ was added to $2 \mathrm{ml}$ of MTS $(2 \mathrm{mg} / \mathrm{ml}), 20 \mu \mathrm{l}$ of the MTS/PMS solution were added to $100 \mu \mathrm{l}$ of serum free medium and incubated with cells for $2 \mathrm{~h}$ at $37^{\circ} \mathrm{C}$ with mechanical shaking $(150 \mathrm{rpm})$. The absorbance was measured at $490 \mathrm{~nm}$ using a microplate reader (Molecular Devices Corporation, Sunnyvale, CA, USA). The dehydrogenase activity in untreated cells (i.e., cells without peptide treatment) was set at $100 \%$, and the toxic effect of CPP peptides measured as the relative decrease in enzyme activity.

\section{$R P-H P L C$}

Permeability study samples of CF-labeled hCT-derived peptides, Tat(47-57), and CF were analyzed by RP-HPLC. A 
system consisting of a L-7100 pump, an L-7200 autosampler and a L-7485 fluorescence detector (Merck-Hitachi, VWR International, Dietikon, Switzerland) was used. A flow rate of $1 \mathrm{ml} / \mathrm{min}$ and fluorescence emission detected at $517 \mathrm{~nm}$ with excitation at $492 \mathrm{~nm}$ was applied. For analysis of the hCT peptides and $\mathrm{CF}$, the system was equipped with a MicrosorbMV100 C18 $(150 \mathrm{~mm} \times 4.6 \mathrm{~mm}, 5 \mu \mathrm{m})$ column (Varian, Zug, Switzerland). The gradient was linear from $10 \%$ solvent A (AcCN:water:TFA, 80:19.99:0.01)(v/v/v) and 90\% solvent B (AcCN:water:TFA, 10:89.99:0.01)(v/v/v) to $20 \%$ solvent B over $30 \mathrm{~min}$. The approximate retention times of CF-labeled hCT(9-32), hCT(12-32), hCT(15-32), hCT(18-32), hCT(2132), CF and random sequence hCT(9-32) were 22, 19, 21, 18, 14,13 , and 20, respectively. For analysis of Tat(47-57) and penetratin(43-58), a LiChrospher 100 RP-18 column $(250 \mathrm{~mm}$ $\times 4 \mathrm{~mm}, 5 \mu \mathrm{m})$ (Merck KGaA, Darmstadt, Germany) was used. Again a linear gradient was applied, starting at $90 \%$ solvent A (water:TFA, 99.9:0.1) (v/v) and 10\% solvent B (AcCN:TFA, 99.925:0.075) (v/v) to $100 \%$ solvent B over 41 min. To avoid adhesion of Tat(47-57) in the system, a washing step with acetic acid succeeded each injection. The approximate retention time was $17 \mathrm{~min}$ for Tat(47-57) and $22 \mathrm{~min}$ for penetratin(43-58). For CF as well as the CF-labeled peptides, the limit of detection was approximately $2.5 \times 10^{-8} \mathrm{M}$.

\section{Data Analysis}

The effective permeability coefficients, P, were determined at steady state according to Eq. (1):

$$
\mathrm{P}=\left(\frac{\mathrm{dC}}{\mathrm{dt}}\right)_{\mathrm{ss}} \frac{\mathrm{V}}{\mathrm{A} \cdot \mathrm{C}_{\mathrm{D}}}
$$

where $(\mathrm{dC} / \mathrm{dt})_{\mathrm{ss}}$ is the steady-state slope of the concentration vs. the time profile in the receiver compartment (corrected for sample removal), $\mathrm{A}$ is the cross-sectional area of the filter membrane, $\mathrm{V}$ is the volume in the receiver chamber, and $\mathrm{C}_{\mathrm{D}}$ is the initial concentration in the donor compartment.

Effective permeability values were determined as both $\mathrm{P}_{\text {intact }}$ and $\mathrm{P}_{\text {cumul }}$. $\mathrm{P}_{\text {intact }}$ is based on the analysis of intact peptide alone as quantified by RP-HPLC. $\mathrm{P}_{\text {cumul }}$ is the cumulative permeability related to the cumulated fluorescence of all species in the receiver chamber still carrying the CF cargo, that is, intact peptide plus $N$-terminal metabolites detectable in the receiver samples. Hence, $\mathrm{P}_{\text {intact }}$ accounts for the permeability of the intact CF-labeled peptide alone, whereas $\mathrm{P}_{\text {cumul }}$ is a measure for the permeability of ligated $\mathrm{CF}$, irrespective of whatever peptide residues remain conjugated. No permeation of free CF was observed upon cellular metabolism. $\mathrm{P}_{\text {cumul }}$ has practical relevance for the cellular translocation of the attached cargo.

The intensity of CF-based fluorescence was observed to decrease with decreasing amounts of $\mathrm{AcCN}$ in the mobile phase. A linear decrease with the percentage of solvent A $\left(\mathrm{S}_{\mathrm{A}}\right)$ used for RP-HPLC of hCT peptides was found [Eq. (2)].

Fluorescence intensity $=-9.1 \times$ percentage of $\mathrm{S}_{\mathrm{A}}+804.6$

Therefore, the area under curve (AUC) values of all observed RP-HPLC peaks were normalized before calculating the permeability of the tested CPP. As a standard, peak areas were normalized relative to a mix of $50 \%$ solvent $\mathrm{A}$ and $50 \%$ solvent B. Briefly, for intact peptide and each fluorescent metabolite, the percentages of solvent $\mathrm{A}$ at the respective retention times were calculated. For each of the peaks, a factor corresponding to the ratio between the fluorescence intensity at the respective percentage of solvent A and a standard percentage of $50 \%$ solvent A was calculated. The peak areas of the intact peptide and each metabolite were multiplied by this factor in order to transform experimental AUC into normalized AUC at $50 \%$ solvent A. Cumulated normalized AUC were calculated for each time point to create the respective permeation profile which was then used to calculate $\mathrm{P}_{\text {cumul }}$.

The integrity of the cell culture layers monitored before and after each permeability study by measuring the TEER was represented as resistance in $\Omega \cdot \mathrm{cm}^{2}$, corrected for the filter without cells and normalized to surface area.

Statistical data analysis was performed using the Student's $t$ test with $\mathrm{p}<0.05$ as the lowest level of significance.

\section{RESULTS}

\section{Cellular Uptake of CF-Labeled hCT-Derived Peptides, Tat(47-57), and Penetratin(43-58)}

Confocal laser scanning microscopy (CLSM) micrographs of cellular peptide uptake in Calu-3 monolayers and TR146 multilayers were compared to CLSM images (images A-D, Fig. 1) from a previous uptake study in MDCK monolayers (15). A complete array of micrographs is given in Fig. 1. No intracellular fluorescence was observed when the cells were incubated with negative controls, that is, no peptide (Figs. 1A, 1E, 1I). Further, equimolar amounts of unconjugated $\mathrm{CF}$ did not result in intracellular fluorescence; yet, in both Calu-3 and TR146 cells extracellular fluorescence was observed (data not shown). The CPP hCT(9-32) and hCT(1232) demonstrated an identical, punctuated cytoplasmic pattern with a sectorial distribution in the MDCK model (15). For representation, the intracellular distribution pattern of hCT(12-32) is illustrated in Fig. 1B. Equally, Tat(47-57) depicted a cytoplasmic and punctuated pattern, but with a uniform distribution across the MDCK monolayers (Fig. 1C). With penetratin(43-58), a concomitant staining of the surface of the plasma membrane in addition to intracellular vesicles was observed (Fig. 1D). In Calu-3 cell monolayers, hCT(9-32) demonstrated an extracellular distribution, indicating a paracellular accumulation of the fluorescence (Fig. 1F). Both Tat(47-57) and penetratin(43-58) depicted punctuated cytoplasmic as well as extracellular staining in Calu-3 cells (Figs. $1 \mathrm{G}$ and $1 \mathrm{H})$. By contrast, the hCT(9-32) peptide in TR146 cells showed both punctuated cytoplasmic and extracellular distribution (Fig. 1J), whereas Tat(47-57) showed mainly extracellular staining (Fig. 1K) and penetratin(43-58) a punctuated cytoplasmic pattern (Fig. 1L). In neither of the studies, significant peptide fluorescence was observed inside the nuclei. In a previous study, we demonstrated that both fixed and non-fixed MDCK cells showed a punctuated cytoplasmic distribution of the peptides (15).

\section{Transepithelial Permeability of CF-Labeled hCT-Derived Peptides and Tat(47-57)}

The permeability coefficients for the paracellular markers decreased with increasing MW and for the three epithelial 
Control
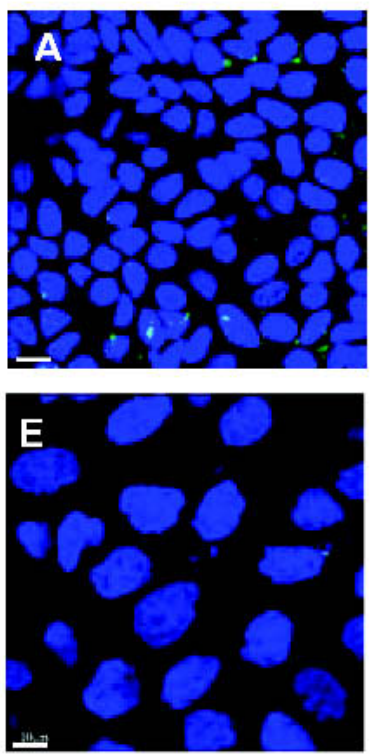

Calu-3

MDCK

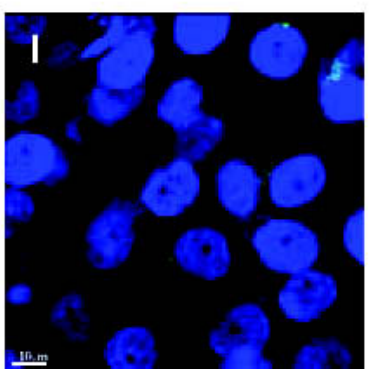

hCT
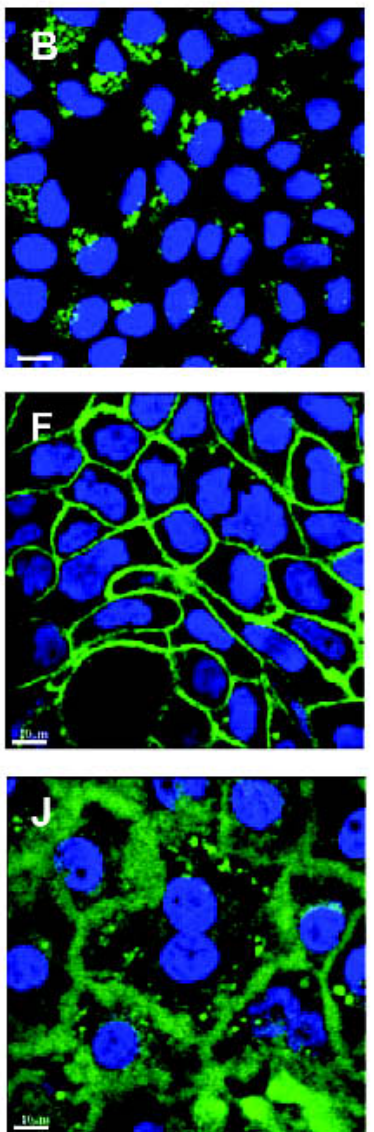

Tat(47-57)
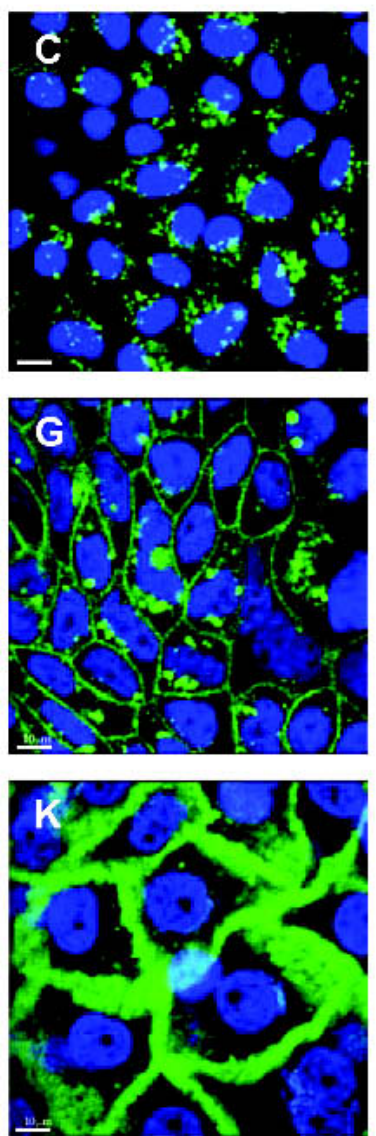

penetratin(43-58)
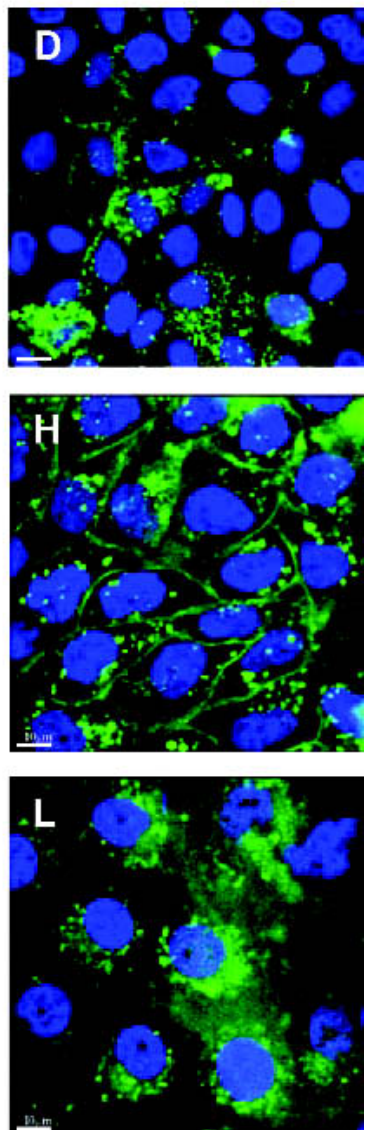

Fig. 1. Variable CLSM patterns of cellular uptake of hCT-derived peptides, Tat(47-57), and penetratin(43-58) in confluent and fully differentiated MDCK monolayers (images A-D) (15), Calu-3 cell monolayers (images E-H), and TR146 cell multilayers (images I-L). Cell layers were incubated without peptide (images A, E, I), with $40 \mu \mathrm{M} \mathrm{hCT}(12-32)$ (image B), $40 \mu \mathrm{M}$ hCT(9-32) (images F and J), 10 $\mu$ M Tat(47-57) (images $\mathrm{C}, \mathrm{G}, \mathrm{K}$ ), or $10 \mu \mathrm{M}$ penetratin(43-58) (images D, H, L). The cell nuclei are shown in blue and the peptides in green. Processed CLSM data sets are illustrated as xy-sections. Bars: $10 \mu \mathrm{m}$.

models, the order MDCK < Calu-3 < TR146 was observed (Table II). An exception was mannitol, which had a similar $\mathrm{P}$ value in the MDCK and Calu-3 model. In general, however, the $\mathrm{P}$ values for the $\mathrm{CF}$-labeled hCT-derived peptides and Tat(47-57) were lower than those of PEG4000 (Fig. 2). In MDCK, the peptides showed $\mathrm{P}$ values, both $\mathrm{P}_{\text {intact }}$ and $\mathrm{P}_{\text {cumul }}$, which were significantly lower than that of PEG4000. In Calu-3, hardly any intact peptides were found in the receiver compartments except for Tat(47-57). In these cases, estimations of permeability coefficients were exclusively based on $\mathrm{P}_{\text {cumul }}$. In TR146 cell layers, however, the permeability of the peptides was similar to PEG4000. A significant exception from this rule was the peptide hCT(21-32), demon-

Table II. Permeability of ${ }^{3}[\mathrm{H}]$-Mannitol, ${ }^{3}[\mathrm{H}\}$-PEG900, and ${ }^{3}[\mathrm{H}]$ PEG4000 Across the Cell Culture Models Used*

\begin{tabular}{lccc}
\hline & $\begin{array}{c}{ }^{3}[\mathrm{H}]-\text { mannitol } \\
\left(10^{-7} \mathrm{~cm} / \mathrm{s}\right)\end{array}$ & $\begin{array}{c}{ }^{3}[\mathrm{H}]-\mathrm{PEG} 900 \\
\left(10^{-7} \mathrm{~cm} / \mathrm{s}\right)\end{array}$ & $\begin{array}{c}\left.{ }^{3} \mathrm{H}\right]-\mathrm{PEG} 4000 \\
\left(10^{-7} \mathrm{~cm} / \mathrm{s}\right)\end{array}$ \\
\hline MDCK & $7.87 \pm 2.25$ & $3.54 \pm 0.71$ & $1.43 \pm 0.54$ \\
Calu-3 & $6.12 \pm 1.19$ & $6.32 \pm 0.56$ & $3.30 \pm 0.26$ \\
TR146 & $53.0 \pm 13.9$ & $26.0 \pm 6.15$ & $11.9 \pm 0.96$ \\
\hline
\end{tabular}

$*$ Mean \pm SD $(\mathrm{n}=3)$. strating a $\mathrm{P}_{\text {cumul }}$ comparable to PEG4000 in Calu-3 monolayers, and to PEG900 in TR146 monolayers, respectively. Interestingly, Tat(47-57) demonstrated $\mathrm{P}$ values similar to those of hCT-derived peptides in each of the cell line models.

The $\mathrm{P}$ value for $\mathrm{CF}$ permeability across the epithelia was 4.5- to 8.5-fold above that of the peptides. The fluorophore was therefore not a limiting factor for the transfer of the peptides (data not shown). Further, all the tested compounds, except penetratin(43-58), showed significantly higher permeability across filters without cells as compared to filters with cells. With MDCK and Calu-3, the differences were at least in the range of one order of magnitude (data not shown). For TR146, the difference was lower, that is, about 4- to 6-fold, but still significant. The low permeability coefficient of penetratin(43-58) across the filter without cells $(1.35 \pm 0.62 \times$ $10^{-6} \mathrm{~cm} / \mathrm{s}$ ) may be explained by interaction of the peptide with the filter. Therefore, penetratin(43-58) was not further considered for interpretation in the permeability study. The $P$ values were similar in collagen-coated filters as used for the Calu-3 cell culture (data not presented). The TEER values were $111 \pm 21 \Omega \cdot \mathrm{cm}^{2}(\mathrm{n}=68), 362 \pm 86 \Omega \cdot \mathrm{cm}^{2}(\mathrm{n}=54)$ and $164 \pm 79 \Omega \cdot \mathrm{cm}^{2}(\mathrm{n}=58)$ for MDCK, Calu-3, and TR146, respectively, and consistent with previously reported data (23, 

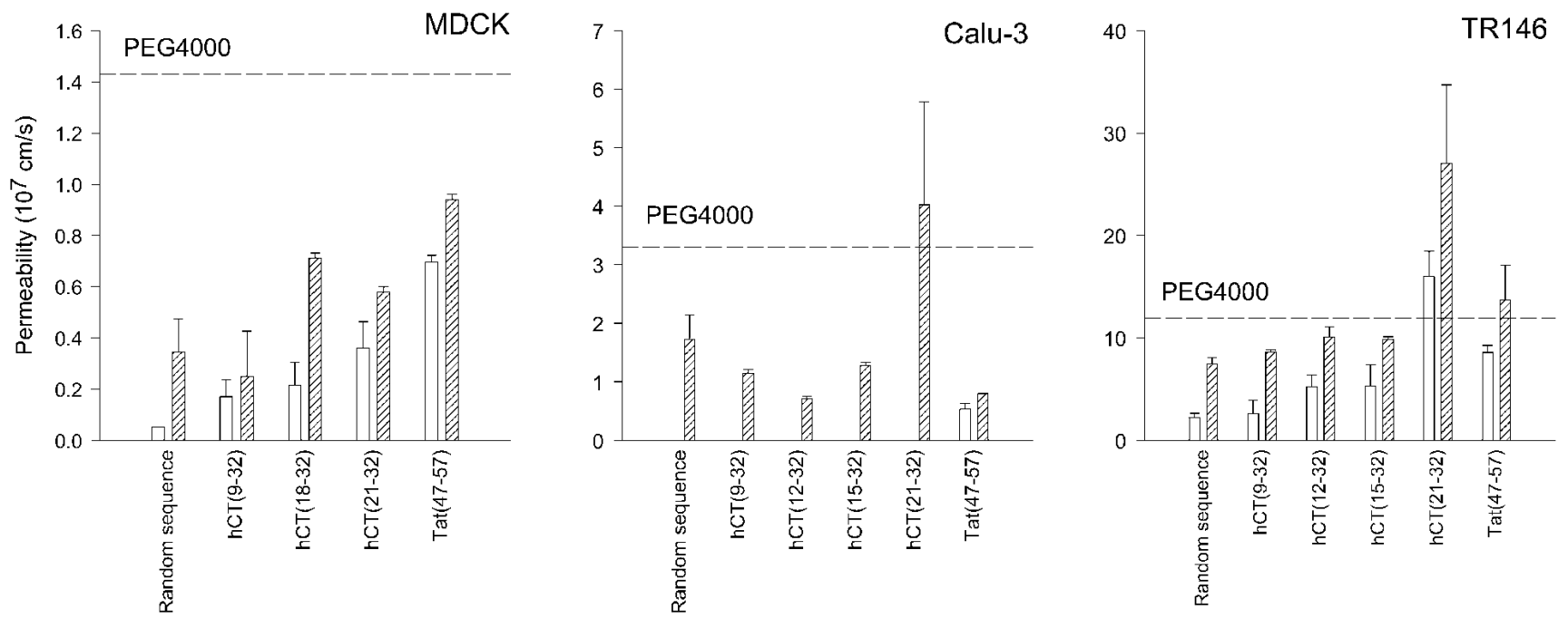

Fig. 2. Effective permeability coefficients of the CF-labeled hCT-derived peptides and Tat(47-57) in three epithelial models: MDCK, Calu-3, and TR146. Permeability coefficients of intact peptides, $P_{\text {intact }}$, (open bars), and cumulative permeability coefficients, $P_{\text {cumul }}$, of intact peptides and N-terminal metabolites carrying the fluorescent cargo (scattered bars) are presented. Mean \pm SD $(n=3)$. The dashed line indicates the $\mathrm{P}$ value for PEG4000 in each of the cell lines.

30,31). No significant changes in the TEER values were detected during the $6 \mathrm{~h}$ of the permeation experiments.

\section{Metabolism of CF-Labeled hCT(9-32) and Tat(47-57)}

When incubated in the presence of the three epithelial models, the peptides were subject to enzymatic degradation leading to the appearance of various metabolites. It emerges from Fig. 3 that the metabolism of hCT(9-32) upon adminis- tration to the Calu-3 model was almost complete within 60 min generating four to five main $\mathrm{N}$-terminal metabolites. For MDCK, the metabolism of hCT(9-32) seems significantly slower, which was also observed with TR146. Contrastingly, Tat(47-57) was metabolically rather stable in all cell lines (data not shown). In the RP-HPLC chromatograms, no free $\mathrm{CF}$ was detected as a result of metabolic cleavage upon permeation of the cell layers. Further, the emitted fluorescence intensity of CF was not affected by the degree of metabolism
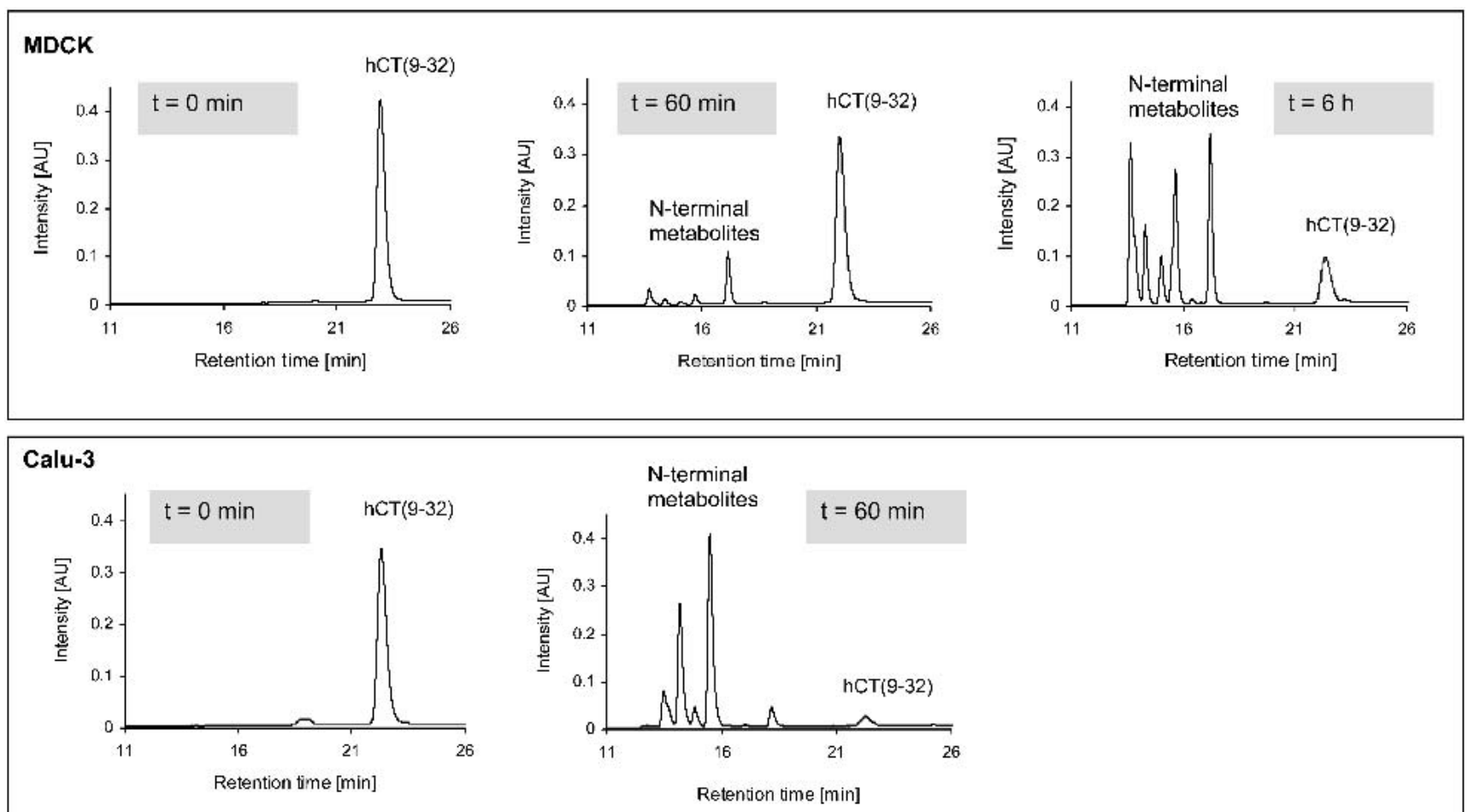

Fig. 3. RP-HPLC chromatograms illustrating the metabolic degradation of $40 \mu \mathrm{M}$ CF-labeled hCT(9-32) upon apical application to MDCK or Calu-3 layers. 
Table III. Cumulated Fluorescence Intensity $\left(\lambda_{\mathrm{ex}} 492 \mathrm{~nm}, \lambda_{\mathrm{em}} 517\right.$ $\mathrm{nm})$ During Metabolism of $40 \mu \mathrm{M}$ CF-Labeled hCT(9-32) by Calu-3 Epithelium*

\begin{tabular}{lccc}
\hline & \multicolumn{3}{c}{ Relative fluorescence (AU) } \\
$\mathrm{t}=0 \mathrm{~min}$ & $\mathrm{t}=20 \mathrm{~min}$ & $\mathrm{t}=40 \mathrm{~min}$ & $\mathrm{t}=60 \mathrm{~min}$ \\
\hline $613.7 \pm 5.3$ & $611.0 \pm 8.3$ & $630.5 \pm 51.9$ & $660.1 \pm 40.9$ \\
\hline
\end{tabular}

The cumulated fluorescence intensities of intact peptide and metabolites remain essentially constant, that is, the slope of the linear fluorescence versus time regression is not statistically different from zero $(\mathrm{p}>0.05)$.

Mean \pm SD $(n=3)$.

(Table III), that is, quantitation by fluorescence detection and calculation of $\mathrm{P}_{\text {cumul }}$ is not compromised by the extent of metabolism and thus do not require detailed knowledge of the rate and kinetics of metabolism.

\section{Cytotoxicity of CF-Labeled hCT-Derived Peptides, Tat(47-57), and Penetratin(43-58)}

In Table IV, the percentages of viable cells after $2 \mathrm{~h}$ are given. No significant differences between the 2-h observations and shorter or longer incubation periods were observed. Even at concentrations of up to $100 \mu \mathrm{M}$ and after $24 \mathrm{~h}$ of incubation, hCT-derived peptides, Tat(47-57) and penetratin(43-58) did not show relevant toxicity (i.e., enzyme activity $>90 \%$ ) in the three cell types. The exception was penetratin(43-58), which was observed to be slightly toxic in TR146 even upon application of $10 \mu \mathrm{M}$. The loss of viability in TR146 was $12-24 \%$ when incubated at concentrations of 10 to $100 \mu \mathrm{M}$, as early as after $1 \mathrm{~h}$ of treatment. Longer incubation times further decreased the enzyme activity to about $37 \%$. Both Tat(47-57) and penetratin(43-58) showed significant toxicity at the highest concentration $(1000 \mu \mathrm{M})$ in all three epithelial models, as detected as early as after $1 \mathrm{~h}$ of incubation. Incubation with $1 \mathrm{mM} \mathrm{CF}$ did not reveal any indication of toxicity in any of the applied cell models, even after $24 \mathrm{~h}$ (data not shown). The viability of cells incubated with $70 \%(\mathrm{v} / \mathrm{v})$ ethanol as a positive control decreased approximately $85 \%(\mathrm{v} / \mathrm{v})$ within $2 \mathrm{~h}$ of incubation (data not shown).

\section{DISCUSSION}

In the current study, the cellular uptake and the permeability of CF-labeled hCT-derived peptides, Tat(47-57), and penetratin(43-58) in three established epithelial cell culture models were assessed. By CLSM, it was demonstrated that depending on the peptide and the applied epithelial model, selected peptides were in fact internalized, whereas others showed extracellular binding only. The metabolic cleavage might account for the differences in localization patterns, as the extent of metabolism seemed dependent on the peptide, the applied epithelial model and the exposure time. At this point, the nature of these remarkably contrasting patterns of intracellular vs. paracellular localization is unknown. Nevertheless, the data calls a cell-type independent mechanism of CPP internalization $(4,33)$ strongly into question. This confirms a previous suggestion of Koppelhus et al., who argued that the uptake might depend on cell-specific membrane components or lipid composition (12). However, the internalization efficiency and/or internalization rate of Tat(47-57) and penetratin(47-57) might be different from that of hCT(9-32) and hCT(12-32) because lower concentrations were sufficient to obtain CLSM images. Moreover, our data question the practical relevance of uptake studies with proliferating cells only. Apparently, fully organized epithelial-type cultures show much better discrimination of cellular entry.

By CLSM, a purely intracellular uptake of hCT(9-32) in MDCK was demonstrated, but in Calu-3 and TR146 a marked paracellular accumulation correlating with a somewhat better permeation of the peptide and its metabolites across these barriers was observed. In contrast, Tat(47-57), which accumulated partly or exclusively in the paracellular space of Calu-3 and TR146, did not show a higher permeability in these two barriers as compared to MDCK cells. This is in correspondence with a recent study describing that in MDCK and Caco-2 cells, the permeability of Tat(48-57) was restricted to a level similar to the paracellular marker $\left[{ }^{14} \mathrm{C}\right]-$ inulin (19). It may be speculated whether Tat(47-57) has the tendency to strongly interact with the plasma membrane of the cells, hindering its paracellular transport. Furthermore, this might partly explain the recent report that Tat(44-57) could not penetrate plasma membranes of MDCK monolay-

Table IV. Cytotoxicity of Selected, CF-Labeled hCT-Derived Peptides, Tat(47-57), and Penetratin(4358) After $2 \mathrm{~h}$ of Incubation with MDCK, Calu-3, and TR146 Layers

\begin{tabular}{|c|c|c|c|c|c|c|c|}
\hline & \multicolumn{3}{|c|}{ Peptide concentration $(\mu \mathrm{M})$} & \multicolumn{4}{|c|}{ Peptide concentration $(\mu \mathrm{M})$} \\
\hline & 40 & 80 & 100 & 10 & 50 & 100 & 1000 \\
\hline & \multicolumn{3}{|c|}{$\mathrm{hCT}(9-32)$} & \multicolumn{4}{|c|}{ Tat $(47-57)$} \\
\hline MDCK & $99.6 \pm 0.15$ & $102.0 \pm 0.16$ & $101.8 \pm 0.21$ & $97.7 \pm 0.09$ & $98.1 \pm 0.13$ & $98.2 \pm 0.11$ & $36.0 \pm 0.09$ \\
\hline Calu-3 & $97.2 \pm 0.14$ & $97.7 \pm 0.10$ & $99.3 \pm 0.14$ & $96.0 \pm 0.11$ & $98.9 \pm 0.15$ & $99.3 \pm 0.14$ & $65.4 \pm 0.18$ \\
\hline TR146 & $99.8 \pm 0.08$ & $102.8 \pm 0.05$ & $104.2 \pm 0.05$ & $94.1 \pm 0.20$ & $96.4 \pm 0.15$ & $96.0 \pm 0.13$ & $48.4 \pm 0.16$ \\
\hline & \multicolumn{3}{|c|}{ hCT(18-32)/hCT(12-32)* } & \multicolumn{4}{|c|}{ Penetratin(43-58) } \\
\hline MDCK & $98.8 \pm 0.23$ & $104.7 \pm 0.23$ & $103.1 \pm 0.21$ & $93.5 \pm 0.19$ & $95.0 \pm 0.12$ & $92.2 \pm 0.16$ & $40.9 \pm 0.31$ \\
\hline Calu-3 & $98.6 \pm 0.09$ & $98.8 \pm 0.02$ & $98.8 \pm 0.08$ & $95.9 \pm 0.10$ & $95.0 \pm 0.05$ & $90.6 \pm 0.96$ & $70.6 \pm 0.11$ \\
\hline TR146 & $99.2 \pm 0.05$ & $101.2 \pm 0.08$ & $100.8 \pm 0.05$ & $83.0 \pm 0.19$ & $88.0 \pm 0.31$ & $76.4 \pm 0.58$ & $44.8 \pm 0.09$ \\
\hline
\end{tabular}

The data represents the percentage of viable cells relative to a negative control (i.e., cells without peptide treatment). Mean \pm SD $(n=4)$. The concentrations used for uptake and permeability studies are highlighted.

* hCT(18-32) was incubated with MDCK cell layers; hCT(12-32) with Calu-3 and TR146 layers. 
ers (20), contradicting however our results with Tat(47-57). The present result that the epithelium is the limiting barrier for permeability of penetratin(43-58) is in contrast to a recent study (21).

It was demonstrated that the selected hCT-derived peptides and Tat(47-57) as well as their concomitantly formed $\mathrm{N}$-terminal metabolites revealed only poor permeation through the three established epithelial cell cultures. Their permeability values were in the range or even lower than those of markers of comparable molecular weights commonly used to demonstrate passive, paracellular transport. By RPHPLC, a distinction between intact peptide and N-terminal metabolites thereof was possible. The cumulative permeability coefficients, $\mathrm{P}_{\text {cumul }}$, were generally higher than those of intact peptide, $\mathrm{P}_{\text {intact }}$. This strongly indicates the effect of metabolic degradation of the hCT peptides when crossing the epithelia, and that, though to a rather limited degree, both intact peptides and N-terminal metabolites cross the barrier. Though in Calu-3, Tat(47-57) was capable of delivering intact peptide into the receiver-at low efficiency, however-all of the other tested CPP were almost entirely metabolized before reaching the receiver compartment. The metabolic capacity of the other epithelial models, MDCK and TR146, seemed markedly lower. However, as even the metabolically more stable Tat(47-57) did not show appreciable levels of cargo permeation, the predominant role of metabolism to explain the poor levels of CPP permeation in this study must be excluded. Overall, once translocated into cytoplasmic compartments, the presently tested peptides did not efficiently permeate the epithelium. The peptide hCT(21-32) was recently observed not to internalize into MDCK cells (15). The absence of internalization could account for the somewhat higher $\mathrm{P}$ of this peptide, even though the lower MW and metabolism would also contribute to easier diffusion across the epithelial barriers.

The fact that none of the peptides decreased the TEER of the epithelial barriers probably explains the low permeability as compared to transportan and its analog, transportan10 (21). Regarding CPP cytotoxicity, only limited information is available on the cellular toxicity of Tat and penetratin. Jia et al., for example, demonstrated that the cysteine-rich and basic domain of Tat peptide induced endothelial cell apoptosis (34), and Vives et al. showed that $100 \mu \mathrm{M}$ of Tat(37-60) and Tat(37-53) led to a drop in cell viability of HeLa cells, whereas the peptides Tat(43-60) and Tat(48-60) did not induce any significant toxicity during a period of $24 \mathrm{~h}$ (6). For penetratin(43-58), it has been shown that intrastriatal injection of $10 \mu \mathrm{g}$ caused neurotoxic cell death and $50 \mu \mathrm{M}$ induced a cytotoxic effect on U2OS osteosarcoma cells (7). In the current study, Tat(47-57) and penetratin(43-58) demonstrated a toxic effect on MDCK, Calu-3, and TR146 only at the highest concentration $(1000 \mu \mathrm{M})$. When incubated under the same experimental conditions as in the uptake and permeability experiments, the hCT-derived peptides and Tat(4757) turned out to be nontoxic, and only penetratin(43-58) revealed a slightly toxic effect, but exclusively in TR146 cells. As revealed by CLSM, its cytoplasmic uptake pattern was punctuated, suggesting vesicular localization. Koppelhus et al. argued that in case of a toxic effect, a strong diffuse staining of both the cytoplasm and the nuclei could be seen, instead of a vesicular pattern (12). In summary, except for the unrealistically high concentration described above, no significant toxicity of CF-labeled hCT-derived peptides, Tat(47-57), and penetratin(43-58) could be detected when incubated with the three epithelial models. These results are consistent with previous data performed on MDCK cell monolayers using the LDH release method (15). Cell line dependent differences in cellular toxicity may depend on cell-specific membrane components or lipid compositions. The observed extent of toxicity owed to the peptides themselves and not to the fluorophore.

In conclusion, the results show that even after cellular uptake, none of the hCT-derived peptides nor Tat(47-57) demonstrates therapeutically relevant transepithelial permeability in the investigated epithelial models. Remarkably, none of the peptides, except penetratin(43-58) on TR146, showed any cellular toxicity in the three cell lines tested at concentrations as high as $100 \mu \mathrm{M}$ CPP during $24 \mathrm{~h}$. We suggest that, once internalized, the peptides cannot permeate the basolateral barrier of the cells in significant numbers, neither intact nor after cleavage to a N-terminal metabolite carrying the fluorescent cargo. When accumulated in the paracellular space, slightly better permeability values resulted. Hence, the investigated cell penetrating peptide sequences have no relevant potential for systemic drug delivery across epithelia. Expectations raised upon the study by Schwarze et al. (1) in mice, which suggested more or less unlimited access to many organs and tissues, must therefore be reconsidered. In fact, the use of CPP for systemic drug delivery in vivo seems to be questionable, leaving the option of localized delivery of cargos to epithelial or other tissues.

\section{ACKNOWLEDGMENTS}

The authors acknowledge the following contributions: Professor Heidi Wunderli-Allenspach (ETH Zurich) for the opportunity to work with the confocal microscope, Dr. Stefan R. K. Hoffmann (University of Zurich) for the purification of Tat(47-57) and penetratin(43-58), Ruth Alder (ETH Zurich) for help and advice with RP-HPLC, and Riccarda Lucio for contribution in the evaluation of cell toxicity. This work was supported by ETH Zurich, research project number 0-2070299, and the Commission of the European Union (EU project on Quality of Life and Management of Living Resources, project no. QLK2-CT-2001-01451). Further, the project was supported by a grant from the Alfred Benzon Foundation to Hanne M. Nielsen.

\section{REFERENCES}

1. S. R. Schwarze, A. Ho, A. Vocero-Akbani, and S. F. Dowdy. In vivo protein transduction: delivery of a biologically active protein into the mouse. Science 285:1569-1572 (1999).

2. A. Prochiantz. Getting hydrophilic compounds into cells: lessons from homeopeptides. Curr. Opin. Neurobiol. 6:629-634 (1996).

3. L. A. Kueltzo and C. R. Middaugh. Potential use of non-classical pathways for the transport of macromolecular drugs. Expert Opin. Investig. Drugs 9:2039-2050 (2000).

4. M. A. Bogoyevitch, T. S. Kendrick, D. C. Ng, and R. K. Barr. Taking the cell by stealth or storm? Protein transduction domains (PTDs) as versatile vectors for delivery. DNA Cell Biol. 21:879894 (2002).

5. C. H. Tung and R. Weissleder. Arginine containing peptides as delivery vectors. Adv. Drug Deliv. Rev. 55:281-294 (2003).

6. E. Vives, P. Brodin, and B. Lebleu. A truncated HIV-1 Tat protein basic domain rapidly translocates through the plasma membrane and accumulates in the cell nucleus. J. Biol. Chem. 272: 16010-16017 (1997).

7. S. J. Bolton, D. N. Jones, J. G. Darker, D. S. Eggleston, A. J. 
Hunter, and F. S. Walsh. Cellular uptake and spread of the cellpermeable peptide penetratin in adult rat brain. Eur. J. Neurosci. 12:2847-2855 (2000).

8. C. Garcia-Echeverria, L. Jiang, T. M. Ramsey, S. K. Sharma, and Y. P. Chen. A new Antennapedia-derived vector for intracellular delivery of exogenous compounds. Bioorg. Med. Chem. Lett. 11: 1363-1366 (2001).

9. H. Nagahara, A. M. Vocero-Akbani, E. L. Snyder, A. Ho, D. G. Latham, N. A. Lissy, M. Becker-Hapak, S. A. Ezhevsky, and S. F. Dowdy. Transduction of full-length TAT fusion proteins into mammalian cells: TAT-p27Kip1 induces cell migration. Nat. Med. 4:1449-1452 (1998).

10. A. Astriab-Fisher, D. Sergueev, M. Fisher, B. R. Shaw, and R. L. Juliano. Conjugates of antisense oligonucleotides with the Tat and antennapedia cell-penetrating peptides: effects on cellular uptake, binding to target sequences, and biologic actions. Pharm. Res. 19:744-754 (2002).

11. M. Pooga, U. Soomets, M. Hallbrink, A. Valkna, K. Saar, K. Rezaei, U. Kahl, J. X. Hao, X. J. Xu, Z. Wiesenfeld-Hallin, T. Hokfelt, T. Bartfai, and U. Langel. Cell penetrating PNA constructs regulate galanin receptor levels and modify pain transmission in vivo. Nat. Biotechnol. 16:857-861 (1998).

12. U. Koppelhus, S. K. Awasthi, V. Zachar, H. U. Holst, P. Ebbesen, and P. E. Nielsen. Cell-dependent differential cellular uptake of PNA, peptides, and PNA- peptide conjugates. Antisense Nucleic Acid Drug Dev. 12:51-63 (2002).

13. V. P. Torchilin, R. Rammohan, V. Weissig, and T. S. Levchenko. TAT peptide on the surface of liposomes affords their efficient intracellular delivery even at low temperature and in the presence of metabolic inhibitors. Proc. Natl. Acad. Sci. U.S.A. 98: 8786-8791 (2001).

14. L. Josephson, C. H. Tung, A. Moore, and R. Weissleder. Highefficiency intracellular magnetic labeling with novel superparamagnetic-Tat peptide conjugates. Bioconjug. Chem. 10:186-191 (1999).

15. R. Trehin, U. Krauss, R. Muff, M. Meinecke, A. Beck-Sickinger, and H. P. Merkle. Cellular internalization of human calcitonin derived peptides in MDCK monolayers: A comparative study with Tat(47-57) and penetratin(43-58). Pharm. Res. 21:33-42 (2004).

16. S. Lang, B. Rothen-Rutishauser, J. C. Perriard, C. Schmidt, and H. P. Merkle. Permeation and pathways of human calcitonin (hCT) across excised bovine nasal mucosa. Peptides 19:599-607 (1998).

17. M. C. Schmidt, B. Rothen-Rutishauser, B. Rist, A. BeckSickinger, H. Wunderli-Allenspach, W. Rubas, W. Sadee, and H. P. Merkle. Translocation of human calcitonin in respiratory nasal epithelium is associated with self-assembly in lipid membrane. Biochemistry 37:16582-16590 (1998).

18. Z. Machova, C. Muhle, U. Krauss, R. Trehin, A. Koch, H. P. Merkle, and A. G. Beck-Sickinger. Cellular internalization of enhanced green fluorescent protein ligated to a human calcitonin-based carrier peptide. Chembiochem 3:672-677 (2002).

19. S. Violini, V. Sharma, J. L. Prior, M. Dyszlewski, and D. PiwnicaWorms. Evidence for a plasma membrane-mediated permeability barrier to tat basic domain in well-differentiated epithelial cells: lack of correlation with heparan sulfate. Biochemistry 41:1265212661 (2002).

20. S. D. Krämer and H. Wunderli-Allenspach. No entry for TAT(44-57) into liposomes and intact MDCK cells: novel ap- proach to study membrane permeation of cell-penetrating peptides. Biochim. Biophys. Acta 1609:161-169 (2003).

21. M. E. Lindgren, M. M. Hallbrink, A. M. Elmquist, and U. Langel. Passage of cell-penetrating peptides across a human epithelial cell layer in vitro. Biochem. J. 377:69-76 (2004).

22. M. J. Cho, D. P. Thompson, C. T. Cramer, T. J. Vidmar, and J. F. Scieszka. The Madin Darby canine kidney (MDCK) epithelial cell monolayer as a model cellular transport barrier. Pharm. Res. 6:71-77 (1989).

23. B. Q. Shen, W. E. Finkbeiner, J. J. Wine, R. J. Mrsny, and J. H. Widdicombe. Calu-3: a human airway epithelial cell line that shows cAMP-dependent Cl- secretion. Am. J. Physiol. Cell Physiol. 266:493-501 (1994).

24. N. R. Mathias, J. Timoszyk, P. I. Stetsko, J. R. Megill, R. L. Smith, and D. A. Wall. Permeability characteristics of calu-3 human bronchial epithelial cells: in vitro-in vivo correlation to predict lung absorption in rats. J. Drug Target. 10:31-40 (2002).

25. B. I. Florea, M. L. Cassara, H. E. Junginger, and G. Borchard. Drug transport and metabolism characteristics of the human airway epithelial cell line Calu-3. J. Control. Rel. 7:131-138 (2003).

26. H. T. Rupniak, C. Rowlatt, E. B. Lane, J. G. Steele, L. K. Trejdosiewicz, B. Laskiewicz, S. Povey, and B. T. Hill. Characteristics of four new human cell lines derived from squamous cell carcinomas of the head and neck. J. Natl. Cancer Inst. 75:621-635 (1985).

27. J. Jacobsen, B. V. Deurs, M. Pedersen, and M. R. Rassing. TR146 cells grown on filters as a model for human buccal epithelium: I. Morphology, growth, barrier properties, and permeability. Int. J. Pharm. 125:165-184 (1995).

28. H. M. Nielsen, J. C. Verhoef, M. Ponec, and M. R. Rassing. TR146 cells grown on filters as a model of human buccal epithelium: permeability of fluorescein isothiocyanate-labelled dextrans in the presence of sodium glycocholate. J. Control. Rel. 60:223233 (1999).

29. B. Rist, M. Entzeroth, and A. G. Beck-Sickinger. From micromolar to nanomolar affinity: A systematic approach to identify the binding site of CGRP at the human calcitonin gene-related peptide 1 receptor. J. Med. Chem. 41:117-123 (1998).

30. B. Rothen-Rutishauser, S. D. Kramer, A. Braun, M. Gunthert, and $\mathrm{H}$. Wunderli-Allenspach. MDCK cell cultures as an epithelial in vitro model: cytoskeleton and tight junctions as indicators for the definition of age-related stages by confocal microscopy. Pharm. Res. 15:964-971 (1998).

31. H. M. Nielsen and M. R. Rassing. TR146 cells grown on filters as a model of human buccal epithelium: III. Permeability enhancement by different $\mathrm{pH}$ values, different osmolality values, and bile salts. Int. J. Pharm. 185:215-225 (1999).

32. S. Lang, P. Langguth, R. Oschmann, B. Traving, and H. P. Merkle. Transport and metabolic pathway of thymocartin (TP4) in excised bovine nasal mucosa. J. Pharm. Pharmacol. 48:11901196 (1996).

33. T. Suzuki, S. Futaki, M. Niwa, S. Tanaka, K. Ueda, and Y. Sugiura. Possible existence of common internalization mechanisms among arginine- rich peptides. J. Biol. Chem. 277:2437-2443 (2002).

34. H. Jia, M. Lohr, S. Jezequel, D. Davis, S. Shaikh, D. Selwood, and I. Zachary. Cysteine-rich and basic domain HIV-1 Tat peptides inhibit angiogenesis and induce endothelial cell apoptosis. Biochem. Biophys. Res. Commun. 283:469-479 (2001). 